\title{
Papers
}

Explorations into Children's Literature

\section{Politics of Postmodern Multiculturalism in Shaun Tan's The Arrival: Reconfiguring the Subject as a Nomad}

\author{
Ladislava Khailova
}

In Shaun Tan's The Arrival (2006), an intriguing 128-page wordless sequence of sepia-toned images marketed to audiences ranging from middle school-age children to adults, ${ }^{1}$ readers become visually engaged in the main character's struggle to navigate a nameless constructed geographic space-an imaginary New World. Fleeing his serpent-infested Old World homeland and leaving behind two females usually interpreted as his wife and daughter, ${ }^{2}$ the migrant protagonist settles in a New World multi-ethnic community that seamlessly meshes elements of the real with the fantastic. Strange creatures jump out of familiar domestic objects, invented alphabets adorn the walls of a typical cityscape, and peculiar foods are served on the dining tables of an everyday household. As Tan suggests on his website in 'Comments on The Arrival,' such blending of the ordinary and the imaginary, together with the book's genre merging, 'plants the readers...in the shoes of an immigrant character' (Tan 2009). Something like migrants, readers are positioned to leave behind common understandings in attempts to decipher the new society. I argue that the narrative strategies of defamiliarisation and genre blurring, in juxtaposition with the text's deployment of further postmodern techniques (such as conflicting or mutually-exclusive symbolic referents), challenge constructions of the subject as a stable, coherent entity with a clear cultural and geographic affiliation, representing the empowerment of the ex-centric. Specifically, I show that The Arrival, as an example of a postmodern text engaged in the ontological enterprise of decentralisation, promotes the nomadic subject as defined by Rosi Braidotti - $\mathrm{a}$ fractured, polyvalent form of self not tied to a specific nation, place or ideology (Braidotti 1994). As such, the narrative encourages its readers to celebrate a consciousness that resists 
discriminatory normative practices, thus opening a space for traditionally disadvantaged subjects, such as immigrants.

The deployment of postmodern techniques in The Arrival reflects a broader critical trend in contemporary children's and young adult literature which disrupts restrictive identity practices. Recent scholarship has repeatedly pointed out that authors use postmodern strategies to uncover how culture creates meaning and to challenge that meaning. In these discussions, the identification of postmodernism with pluralism, boundary-breaking, and parallelism is a constant strategy to challenge dominant master narratives. For example, Bette P. Goldstone mentions the nonlinearity, self-referentiality, cynical or sarcastic tone as well as the anti-authoritarian, writerly character of many current texts (Goldstone 2001/2002, pp. 363-6). In a more detailed description, Martin Coles and Christine Hall cite multiple pathways through the narratives and plural meanings conveyed by words and images (2001, p. 111). They write, 'In the postmodern it is complexity, a myriad of meanings, rather than one meaning, however profound, which is the norm' (p. 113). Because of this epistemological provisionality and uncertainty, readers are encouraged to engage actively in the construction of the narrative (Coles \& Hall 2001, p. 112). Correspondingly, Coles and Hall add, while modernist texts tend to search for truth, postmodern writings are likely to opt for open endings, extravagantly invented worlds, playfulness and breaking down of barriers, including barriers within audiences (pp. 112-113). Other scholars, pointing to the polyvalence and lack of closure that figure so prominently in definitions of postmodernism, argue that such attempts to systemise the postmodern movement are ultimately futile. Sylvia Pantaleo and Lawrence R. Sipe state, 'creating a binary (postmodern-not postmodern)...is actually antithetical to the spirit of postmodernism itself' (Pantaleo \& Sipe 2008, p. 4). Therefore, they insightfully propose that in view of the variety of characteristics ascribed to the movement, readers think of picture books and other genres as 'located along a continuum of postmodernism' (p. 4). The Arrival's elusive genre identity, along with other postmodern features, unmistakably mark it out as a part of this continuum.

More specifically, Tan's text blurs genres by demonstrating its affinity with both picture books and graphic novels/comic strips. As Barbara Kiefer explains, picture books, published for much of the last century generally as a 32-page hard-bound sequence of images and words centered on a simple story and created for the education and enjoyment of the youngest readerships, began to change significantly in the 1960s as the Vietnam War and 
civil rights movement opened the genre to previously taboo topics and new audiences (Kiefer 2008, p. 9, 19). Authorial tendencies to transcend the conventions of picture books have resulted in the blending of their form and format with those of the comic strip and graphic novel (Kiefer 2008, p. 20). Tan confirms such genre merging in his essay 'The Accidental Graphic Novelist' (Tan 2011). He explains that while he had originally planned to work on a rather traditional 32-page picture book of short written text and no more than double-page illustrations, his ideas gradually grew into a 128-page project which is closer to a graphic novel/comic ${ }^{3}$ with no text and complex sequences of illustrations to match the 'density of [his] subject' (pp. 2-3). Marketing played a major role here, since the Australian publisher accepted Tan's initial outline for a picture book, while the French rights were sold to an enterprise specialising in bande dessinée (denoting comics and graphic novels) and targeting adult audiences (p. 2). In the United States, The Arrival was also advertised as a graphic novel, this time for young adults (p. 2). Accordingly, it is very difficult to categorise the text: Tan's original plans and the pictorial character of the work signal its kinship with traditional children's picture books, while its complexity as a lengthy commentary on the political theme of cultural displacement and belonging mark the text's allegiance to boundary-breaking (young) adult graphic novels. Such blending contributes to The Arrival's postmodern indeterminancy.

A number of critics outline the potential of postmodern indeterminancy for historically peripheral subjects, an issue especially pertinent to The Arrival with its focus on the identity politics of immigration. For example, according to Linda Hutcheon, the decentred perspective empowers all 'the "ex-centric" (be it in class, race, gender, sexual orientation, or ethnicity) [who] take on new significance in the light of the implied recognition that our culture is not really the homogeneous monolith (that is middle-class, male, heterosexual, white, western) we might have assumed' (1988, p. 12). In line with Hutcheon’s argument, Homi Bhabha postulates that the postmodern devaluation of post-Enlightenment grand narratives enables all those who were traditionally pushed to the margins and silenced-'women, the colonized, minority groups, the bearers of policed sexualities'—to reinscribe reality (1994, pp. 4-5).

Rosi Braidotti proposes that the trope of the nomad advances the possibilities that postmodern dispersal generates for non-mainstream subjects (Braidotti 1994). In an introduction to her influential study Nomadic Subjects, she observes, 'the very conditions that are perceived by dominant subjects as factors of a "crisis" of values, are for me the opening 
up of new possibilities. Mors tua vita mea: it is the same historical condition that can be alternatively perceived as positive or negative depending on one's position' (p. 2). She proceeds to develop the concept of nomadic consciousness to accelerate the empowerment of the ex-centric. Braidotti defines the nomad as a heterogeneous minority subject position that rests not on fixity but on mobility and contingency, and as such, is able to free the activity of critical thinking from the hold of dogmatism (pp. 8-31). In her words, 'Though the image of "nomadic subjects" is inspired by the experience of peoples or cultures that are literally nomadic, the nomadism in question here refers to the kind of critical consciousness that resists settling into socially coded modes of thought and behavior. Not all nomads are world travelers; some of the greatest trips can take place without physically moving from one's habitat' (p. 5). Braidotti highlights the political agenda behind such an alternative subject figuration, asserting that it is a form of active resistance to hegemonic rule. She states, 'What is political is precisely this awareness of the fractured, intrinsically power-based constitution of the subject and the active quest for possibilities of resistance to hegemonic formations' (p. 35). She hopes that the nomad trope, defined by her especially in feminist terms but applicable to any postmetaphysical subject (p. 4, 18), will facilitate respect for cultural diversity without falling into political despair-it will restore a sense of intersubjectivity that allows for recognition of differences without exclusions (p. 31, 36).

Tan's The Arrival employs the trope of nomadism as outlined by Braidotti. While depicting the act of migration of the protagonist and other characters from their Old World homelands to the New World without any evidence that they will physically keep on moving-i.e., that they will not geographically settle down in the new space- the book continuously positions the readers to contemplate nomadic subjectivity as an alternative, critical form of consciousness. This is in line with Braidotti's claim that 'It is the subversion of set conventions that defines the nomadic state, not the literal act of traveling' (p. 5). Specifically, through its postmodern narrative devices, The Arrival presents an inspiring vision of characters who form a multiethnic culture that paradoxically combines mobility and multiplicity with coherence to challenge traditional hegemonic hierarchies, such as immigrant/native, center/periphery, and same/other. In this way, The Arrival relies on the nomad trope in its attempt to relinquish the fixity of existing subject positions, inviting all readers to adopt a politically charged nomadic consciousness and to celebrate nondiscriminatory intersubjectivity in the form of boundary-breaking cosmopolitan cultural citizenship. 
A postmodern feature of the text that strongly encourages the adoption of critical consciousness is its ontological emphasis: the narrative attempts to artistically reinvent the world rather than to represent it. Cherie Allan discusses the frequent use of this strategy in current picture books (Allan 2012). While traditionally, these texts tended to represent primarily the everyday world of the child and her/his family, recently picture books have engaged in playfully challenging the boundaries between real and fictional worlds (Allan 2012, p. 80). They foreground the idea that the text is an artifact in order to question the conventional belief that narratives mirror the 'real' world (Allan 2012, p. 80). Karen Coats confirms these observations: according to her, postmodern picture books often call attention to artistic processes with the goal to 'reveal their constructedness' (2008, p. 79). Coats uses the example of Neil Gaiman's The Wolves in the Walls (2003), where the house of Lucy, the main character, is overtaken by wolves that emerge out of her own drawings (p. 79). In Tan's The Arrival, the narrative highlights the artistically constructed character of its worlds by combining historical imagery with elements of fantasy. The sepia tones of its illustrations and its leather-like cover reference historic photography and suggest its resemblance to an aged photo album, evocative of the large immigration waves to New York in the early 1900s. Tan mentions on his website that while the theme of the book deals with migrant experience worldwide without restrictions as to nationality or destination, turn-of-the-century New York, 'a great hub of mass-migration for Europeans,' provided one of the 'main sources for visual reference' to him when working on The Arrival (Tan 2009). ${ }^{4}$ Correspondingly, readers will recognise turn-of-the-century locomotives, steamships, and rustic kitchens as well as allusions to Ellis Island in the drawings. While referring to the recognisable past, the narrative simultaneously infiltrates its images with elements of the fantastic. The Old World cities from which the protagonist and other characters emigrate are haunted by shadowy serpentine monsters and by giants with enormous people-absorbing vacuums. Similarly, its New World inhabitants travel via hot-air balloon elevators and air ships, consume anemonelike foods and have strange animal companions that in themselves are postmodern hybridisations, combinations of several creatures, such as a tadpole and a dog. Such narrative amalgamation of the historic and the fantastic produces an artistically constructed alternate version of reality.

Its depiction of artistically altered historical reality connects The Arrival to historiographic metafiction, identified by Hutcheon as the core of a critically charged postmodern literature 
(1998). Hutcheon describes how novels in this genre are 'both intensely self-reflexive and yet paradoxically also lay claim to historical events and personages,' thus exhibiting strong parodic features in their attempts to highlight the constructed character of history (p. 5). Allan, applying Hutcheon's ideas to postmodern picture books, maintains that many works in the genre can be interpreted as historiographic metafiction, if perhaps in a modified fashion to accommodate the implied audience and relatively short length of picture books (2012, pp. 9798). Allan's analysis of relevant examples includes several works illustrated by Tanspecifically, The Rabbits by John Marsden (1998) and Memorial by Gary Crew (1999). These texts rely on narrative techniques common in historiographic metafiction as it alerts readers to the discursive dimension of historical accounts: The Rabbits offers an alternative perspective on historical events to challenge the 'authorised' version of history; Memorial questions the accuracy of 'documentary' evidence on which a historical report relies (Allan 2012, pp. 98-105). As outlined above, The Arrival uses another metafictive strategy of historiographic metafiction listed by Allan-a mixture of historical and fictive elements (p. 97). By fictionalising accounts of immigration that seem to associate them with turn-of-thecentury immigration waves, The Arrival encourages readers to radically re-imagine such immigration journeys, and, consequently, to critically reevaluate hegemonic views of migrants as ex-centrics. In an interview, Tan states: 'In Australia, people don't stop to imagine what it's like for some of these refugees. They just see them as a problem once they are here' (Margolis 2007, p. 34). He adds that he did not necessarily expect to change readers' negative views of immigrants but was hoping to make them at least 'pause to think' (p. 34). The Arrival's narrative strategy of subversively defamiliarising historical reports in order to encourage anti-hegemonic thinking is directly linked to the concept of critical consciousness as described by Braidotti.

A powerful example of the interrelation between The Arrival's use of altered historic reality and its strategy of defamiliarisation is evident in the series of panels depicting the main character's poster-pasting job. The seemingly aged drawings appear to reference a typical situation of immigration: the newly arrived immigrant's search for employment and the challenges which often accompany such efforts. The main character, having experienced difficulty finding employment in a country whose language(s) he cannot read or speak, finally receives his first work offer: to place posters on the walls of the metropolis. While the readers, like the character, are expected to understand the basic principle of the task-the employer's body language clearly indicates where the posters are to be pasted, how much he 
will pay for completion and what the timeframe is - they are positioned to be equally oblivious as to the message on the posters. The invented, fantastic alphabetical symbols vaguely resemble established systems but are also fundamentally different from them, which makes them indecipherable. Therefore, the readers, similarly to the character, are likely to be surprised when the employer returns and terminates the protagonist's employment immediately. It is only through the employer's gestures that it becomes clear the posters have been hung upside down. Through such textual defamiliarisation of a simple, known activity, the narrative generates a cognitive shock in the audience, highlighting the fact that usual points of reference are invalid in this constructed novelistic space. Scenes like these tend to trigger questions of knowledge-making and epistemological legitimation, positioning readers to consider their own positions.

The effect of constant epistemological destabilisation in The Arrival is accelerated by the inclusion of fluid symbol referents that assume conflicting, often mutually exclusive meanings in the varying cultural contexts the narrative creates. Complex meanings conveyed by images are a common feature of postmodern fiction for young audiences (Coles \& Hall 2001, p. 111). The novel's use of serpent imagery illustrates this representational trend. In the protagonist's country of origin, snake-like shapes with spiky tails loom over the buildings as the family accompanies the departing man, who can be read as the father, to his early morning train - the beginning of his journey abroad. The worried look on the little girl's face as she looks up to the sky indicates that the shapes are the main reason behind the family's impending long-term separation. Correspondingly, the spiky tails suggest suffering, possibly in the form of pogrom, famine, or persecution. Similarly, in the exile stories of other characters, serpentine images are linked to oppressive threat, disaster and death. The World War I army from the older man's memories winds through the soon-to-be-destroyed cities like a snake. In the young girl's story, the industrial smokestacks that constantly have to be supplied by coal, demanding menial, slavish labor and the intellectual starvation of endless females, also echo serpents. In these Old World panels, snake-like shapes thus may be read as confining and containing, communicating an emphasis on uniformity, stagnation, futility and destruction. As such, they are symbolically aligned with totalitarian discourses that erase subjectivities.

In the New World imagery, the serpentine symbol is subject to substantial revision. Occasionally, negative connotations are still present. For instance, at the factory where the 
protagonist finds his third place of employment, the assembly line topped by enormous wheels resembles a grayish serpent, possibly suggesting robotic existence, debilitating repetition, and uniformity-perils of industrialisation-through the type of back-breaking monotonous work it requires. Consequently, the scene is not dissimilar to the young female immigrant's memory of the smokestacks in her homeland. However, unlike the narrative's rendition of the industrial complexes of her home country, the factory in the New World is embedded in space permeated by snake-like images that carry strongly positive symbology. More specifically, in the New York-like metropolis and the natural space depicted outside it, the spiraling lines, often spiked, can be read as signaling play, togetherness, optimism, fluidity, and harmony. To illustrate: shortly after he completes his assembly-line shift, readers find the protagonist engaged in a game where the people, their animals, the playfield, the landscape, as well as the skyscape are organised into eccentric circles partially consisting of spiky lines infused with light. Juxtaposed with the characters' joy of creative play and a sense of camaraderie in spite of their visible differences, the serpentine images of the protagonist's homeland and of the New World assembly line are transformed into what appear to be symbols of inclusiveness and anti-totalitarian values. Similarly, in another New World scene, the readers are likely to share the immigrant's alarm when they discern a spiky tail emerge from a container belonging to his new friends only to learn that, in this particular context, the tail does not embody a menace but is a body part of a cuddly family pet. As a result of such repeated shifts in meanings, readers have to be prepared to reinterpret any of the book's symbolic elements as they metaphorically get to travel with the character through the act of reading. In this way, the readers are transformed into figurative migrants: they are likely to become as out of place as the protagonist and have to learn the conventions of the new country. This potentially uncomfortable position of displacement encourages them to pause to reflect on their stand on immigration and the related issues of assimilation and cultural and ethnic primacy.

The deployment of fluid symbology in The Arrival is evident in its doubling of iconic imagery. At the port of entry into the New World, a magnificent statue complex greets the newly arriving immigrants, including the ship carrying the protagonist. Given its colossal character and location, the artwork is evocative of the Statue of Liberty. However, this wellestablished icon of freedom has undergone a major transformation in the form of doubling. Instead of a single stately figure, two joined figures that constitute one statue are presented to readers. Their different attire, luggage and animal companions suggest their affinity with two 
different cultural systems or, possibly, two varied aspects of one culture. While one figure sports a cone-shaped hat, has a bird perched on his/her shoulder, holds an apple and carries a food jar, teapot and a conical container, the other wears a cylindrical hat, holds a rodent-like creature, and carries a suitcase, vase, and assorted dishes. Importantly, the panoramic image of the diversified figures is free from any hierarchies. Since each figure stands in a small boat containing his/her belongings, readers cannot be sure if they are looking at the representation of two individuals migrating here from another geographic location, two natives passing through the waters surrounding the harbor, or an arriving foreigner and a welcoming native. The equalising impulse behind this depiction of the people(s) of the New World is enhanced by the complementary character of the figures' attributes as well as by the respect they seem to demonstrate for each other. While one provides a tea-pot, the other contributes a tea cupitems which suggest a symbiotic relationship. Also, their backs are arched in a slight bow as if signaling mutual recognition, cooperation, or even friendship, further suggested by their firm handshake and direct eye contact. Such a narrative departure from the dichotomies of the native/immigrant and mainstream/marginal, in concert with the text's destabilisation of boundaries between real and fictional, reader and character, strengthens the novel's postmodern subversion of ideas of ethnocentrism and its advocacy of transitionality and liminality.

The technique of doubling and parallelism, typical in postmodern fiction (Coles \& Hall 2001, p. 112) is repeated in the text in relation to its individual characters. Tan's gift for maintaining a high degree of consistency of visual detail over multiple panels while using various characters emphasises their commonalities. For example, The Arrival tends to zoom from the specifics of the protagonist's immigration journey out to the generality of his experience. Eating dinner in solitude and looking at the picture of his beloved family while on board of the ship carrying him to the New World, the main character appears gradually smaller and smaller in the sequence of panels until he is portrayed as only one of the unrecognisable figures who feature in one of the countless cabins of the large vessel. In an analogous instance of parallelism, revolving again around the protagonist's nostalgic moment over the family photo, the readers see him depicted sitting alone in his first apartment of the New York-like metropolis. The panels gradually re-focus to present a bird-eye view of his position in the tenement building, showing him as just one of the many human shapes in one of the multiple windows. Such progressive distancing highlights the paradigmatic similarities between his life experiences and those of other characters, especially those who also embark 
on an immigration journey and who attempt to settle down in a distant land of opportunity. The narrative focus in these sequences is on the experience of loneliness and a sense of notbelonging, feelings which often accompany migrant endeavours.

The narative juxtaposes this use of the zoom-out technique with a programmatic change in color schemes to emphasise parallels in the characters' rationale for exile. Subtle shifts from brown to grayish-black and the alterations of background panel tones from white to gray and black are used to mark stories detailing the conditions preceding each character's forced departure from a home country. In story after story, readers witness variations on the theme of political oppression and totalitarian control, as previously outlined in the analysis of the serpentine imagery in the text. Through these instances of revised repetition, the book draws attention to the shared human need for safety, food, companionship, and financial and intellectual independence that transcends individual differences. In the constructed space of the narrative, the result is an equalisation which encourages non-exclusionary bonds among individuals.

In support of such nondiscriminatory intersubjectivity, Tan's book shows that commonalities in the personal migrant experiences of the inhabitants of this New World promote acts of solidarity and philanthropy. Braidotti explains the interrelation between empathy and cultural migration (Braidotti 1994). She states, 'Just consider that very settled, anchored, sedentary people are amongst the least empathic, the least easily moved, the most self-consciously 'apolitical.'...By contrast, the nomadic subject functions as a relay team; s/he connects, circulates, moves on; s/he does not form identifications but keeps on coming back at regular intervals' (p. 35). Braidotti adds that it is due to their very transitory nature that migrants are capable of making connections with other subjects (pp. 35-36). By implication, nomadic politics to Braidotti is 'a matter of bonding, of coalitions, of interconnections' with the historic task of restoring a sense of intersubjectivity that would provide for recognition of differences without exclusions (pp. 35-36). The Arrival foregrounds just such fluidity. Tan's characters, having left their home countries, do not appear to pledge allegiance to any narrowly defined social group (e.g., by forming ghettoes and avoiding others in the New World). Rather, the narrative shows that they develop an ability to connect with a broad spectrum of other subject positions. Thus, the sense of caring for one another, regardless of ethnicity, cultural background, age, gender, or class, is present on nearly every page of the narrative. From the first moment the protagonist arrives, he is repeatedly offered help by kind 
strangers, whether in trying to find shelter, comprehend the system of public transportation, identify edible produce or understand the process of food preparation. As a result of such sympathetic assistance, his initial confusion, nostalgia, and loneliness gradually seem to give way to optimism and a sense of community.

The focus on community in the postmodern narrative of The Arrival deserves a closer analysis. Karen Coats argues that characters in postmodern picture books are 'often embedded in communities, or experience the lack of community as a problem to be solved' (Coats 2008, p. 83). Accordingly, she argues that while portraying a fractured, contingent self in a constructed world, these texts do not tend to present the postmodern critique in its nihilistic form (pp. 78-79). ${ }^{5}$ Along the same lines, John Stephens maintains that contemporary picture books appropriate postmodern stylistic traits to 'remain focused on ethical responsibilities and social issues' (Stephens 2008, p. 90). The Arrival's representation of solidarity and empathy among the inhabitants of the New World serves as a good example of such attention to ethical responsibilities. Once the main character becomes fully acquainted with the behavior patterns of his surrounding multicultural environment and can reunite with the two females usually interpreted as his daughter and wife, his family readily returns the favours he received, thus choosing to actively participate in the community building. The narrative closes with the symbolic image of the little girl showing the way to a newly arrived young woman who appears lost. Readers, encouraged to develop a transitory, contingent subjectivity through the act of reading the text, are to an extent dependent on the guidance of the narrative's strangers in order to overcome their own sense of displacement. Thus, the book advocates impulses and acts of sympathy towards the traditionally marginalised.

The closing image of compassion in The Arrival opens space for readings suggesting that the protagonist's family_and, by implication, other immigrant families in the book-become absorbed into the New World at the possible expense of their cultural distinctiveness. After all, the little girl appears so at home in the new culture that she is confident enough to offer guidance to a stranger older than herself. However, other sections of the narrative show that the book's emphasis is on mutual cultural enrichment and coexistence rather than on the effacement of individual differences: the New World's insistence is on unsettled multiculturalism, understood here as variations within the culture. The contents of the protagonist's living quarters attest to that. The opening pages of the first and last chapters, 
depicting everyday objects from his family's life in the Old and New Worlds, illustrate the family's acculturation yet defy the notion of a complete transformation of the characters. For instance, the origami bird of their Old World residence (Chapter I) is replaced by the origami of the family's fantastic pet, which is something between a tadpole and a dog (Chapter VI). Likewise, their New World home features a futuristic clock with a large dial rather than a conventional one, anemone-resembling foods instead of a soup pot, the girl's drawings of air ships instead of her sketches of the family, an innovative stainless teapot rather than a traditional ceramic one, and a newspaper in an invented language instead of a stack of tickets for the transoceanic passage. These changes in object document the cultural adaptation of this group of individuals into the new geographic space, which can also be possibly viewed as the loss of their original culture. However, such an adaptation or potential loss is only partial, since several items remain constant across the cultures. The hat hanging on the hook on the wall is identical in both worlds, as is the attire of the family members in the photographs. This continuity indicates their allegiance to at least two cultural systems or two aspects of the same culture. The result appears to be a fractured, polyvalent self, with the portrayed subject taking on an identity characterised by multiplicity and blending.

The idea of unmarked multidifferentiation of the immigrant culture and the related hybridity of its subjectivites is further developed in the novel through its focus on collective polyglotism. A number of the invented alphabetical characters are repeated in the narrative, and the protagonist develops a picture dictionary containing these characters, which signals the use of a common linguistic medium. This language is used in texts displayed at such vital places as the port, hotels, and food markets. However, the commonality of the system does not preclude the existence of others. The cityscape's billboards and posters show that at least half a dozen other distinctive linguistic structures remain functional within the same cultural space and are used in printed media that tend to be widely distributed, such as books and newspapers. Correspondingly, the novel suggests that while acquiring the language of the new culture, the immigrants also retain the linguistic medium of their home culture as an important element of their polyvalent identity. Braidotti maintains that the ability to communicate in multiple languages is 'a variation on the theme of critical nomadic consciousness' and serves as an important tool in combating the 'exacerbated sense' of ethnocentrism, nationalism, regionalism, and localism that plagues many contemporary cultures (Braidotti 1994, p. 12). She states, 'The polyglot surveys this [political] situation with the greatest critical distance; a person who is in transit between the languages, neither 
here nor there, is capable of some healthy skepticism about steady identities and mother tongues' (p. 12). In accordance with her argument, the cultural nomads of The Arrival, having relinquished the idea of linguistic fixity, ${ }^{6}$ are capable of challenging systems that project the restoration of an allegedly historically justified homogenous polity at the expense of those who do not fit the constricted definition of its centre. The fact that The Arrival opts for a silent narrative, refusing to pin the story down to a particular established language (Yang 2007, p. 21), is in itself a demonstration of the political power of polyglotism and linguistic polyvalence. In making the text conducive to conveying multiple meanings and communicating across languages, its quiet narrative seeks to break boundaries among audiences on an international scale-by not limiting itself to a narrow group of readers from one linguistic group, it treats them as equal.

Shaun Tan has never been particularly shy about articulating his political views. Between the years of 1994 and 1996, he created political cartoons for several student and mainstream newspapers, which influenced his work as an author of picture books and graphic novels that tend to offer political commentary (Tan 2001, p. 5). As for The Arrival, Tan points out its attempt to target discriminatory politics in an interview discussing the composition stage of the text (Tan 2001). He states that immigration is an issue that Australia has to 'grapple with as a nation. [The] recent Federal election, for instance, hinged almost entirely on the issue of Middle Eastern refugees, resulting in a shameful polarising of public attitudes, and a lot of ignorant rhetoric' (p. 75). In line with the author's expressed dissatisfaction with socially coded modes of thought and behavior that foster discrimination of immigrants in the Australian society and worldwide, The Arrival creates a postmodern, culturally decentralised New World that challenges constructions of the subject as a fixed, coherent, geographically and culturally anchored entity. The narrative employs the trope of nomadism to present a politically charged form of consciousness that questions dominant conventions. As such, the book explodes existing inequitable dichotomies in the attempt to include immigrants as historically disadvantaged subjects. Some may argue that the narrative vision of a society based on postmodern multiculturalism can be easily deconstructed because its insistence on polyvalence is, paradoxically, a new form of univalence. Thus, it may hypothetically result in a lack of social participation by those who are less comfortable with fluidity-for instance, immigrants who would prefer to claim exclusive allegiance to their original cultural identity by forming diasporic communities and not associating with others. In spite of these potential limitations, The Arrival's pro-nomadic cosmopolitan cultural polity presents a clear challenge 
to more traditional societal models favoring the hegemony of a narrowly defined group of individuals of a specific national, racial or ethnic origin. Unlike these distinctly monovalent societies, Tan's constructed New Word allows for a non-hierarchical coexistence of a very broad spectrum of cultures. The endpapers of the narrative, consisting of passport photos of small black-and-white portraits of the migrants, attest to that. With the depiction of 'faces of every shape, age and color,' as Yang puts it (Yang 2007, p. 21), discriminatory boundaries among individuals are put to a test: any reader is likely to find an imaginary representative of a culture s/he can identify with in the resulting multicultural mosaic and feel included.

\section{Notes}

1. For opinions about The Arrival's target audience, see, for example, reviews by Abbott (2007, p. 225), Karp (2007, p. 115), and Lempke (2007/2008, p. 34).

2. See, for instance, 'The Arrival' in Publishers Weekly (2007, p.166), Farrell, Arizpe \& McAdam (2010, p.199) and Lempke (2007/2008, p. 34).

3. Tan uses the terms comics and graphic novel interchangeably: to him, they both 'describe an arrangement of words and/or pictures as consecutive panels on a printed page' (Tan 2001, p. 2). He adds that the genre of picture books fits this description as well (p. 2).

4. Tan lists the immigrant experience of the Chinese in Western Australia as another significant source of inspiration (Tan 2009).

5. In the context of the focus on community building in postmodern picture books, Coats' essay explores the relationship of postmodern picture books to the transmodern, defined by her as a 'synthesis and corrective' to both modernist and postmodernist thought (Coats 2008, p. 76). In Coats' words, the transmodern 'seeks to keep the best and most persistent impulses of modernity - the striving for meaning beyond the self, the desire for coherence, the push for freedom-while acknowledging that real limits are imposed on individuals by their bodies, their relationships, their culture, and their language' (p. 81).

6. The invented character of the employed linguistic media in The Arrival further challenges the notion of linguistic systems as fixed. According to Cherie Allan, postmodern picture books often utilise invented languages to draw attention to the arbitrary relationship between 
the signifier and the signified and the unstable character of all meaning (Allan 2012, pp. 58$63)$.

\section{References}

Abbott, Alana. (2007) 'Tan, Shaun. The Arrival’, School Library Journal 53, 9, 225.

Allan, Cherie. (2012) Playing with Picturebooks: Postmodernism and the Postmodernesque. New York, Palgrave Macmillan.

Anonymous (2007) 'The Arrival', Publishers Weekly 254, 28, 166.

Bhabha, Homi K. (1994) 'Introduction: locations of culture', in The Location of Culture. London, Routledge, pp. 1-18.

Braidotti, Rosi. (1994) Nomadic Subjects: Embodiment and Sexual Difference in Contemporary Feminist Theory. New York, Columbia UP.

Coats, Karen. (2008) 'Postmodern picturebooks and the transmodern self', in L. R. Sipe \& S. Pantaleo (eds.) Postmodern Picturebooks: Play, Parody, and Self-Referentiality. New York, Routledge, pp. 75-88.

Coles, Martin \& Hall, Christine. (2001) 'Breaking the line: new literacies, postmodernism and the teaching of printed texts’, Reading 35, 3, 111-114.

Farrell, Maureen, Arizpe, Evelyn \& McAdam, Julie. (2010) 'Journeys across visual borders: annotated spreads of The Arrival by Shaun Tan as a method for understanding pupils' creation of meaning through visual images', Australian Journal of Language and Literacy 33, 3, 198-210.

Goldstone, Bette P. (2001/2002) 'Whaz up with our books?: changing picture book codes and teaching implications', The Reading Teacher 55, 4, 362-370.

Hutcheon, Linda. (1988) A Poetics of Postmodernism: History, Theory, Fiction. New York, Routledge.

Karp, Jesse. (2007) 'The Arrival’. Booklist 104, 1, 115.

Kiefer, Barbara. (2008) 'What is a picturebook, anyway? The evolution of form and substance through the postmodern era and beyond', in Lawrence R. Sipe \& Sylvia Pantaleo (eds.) Postmodern Picturebooks: Play, Parody, and Self-Referentiality. New York, Routledge, pp. 9-21.

Lempke, Susan D. (2007/2008) ‘The Arrival by Shaun Tan’, Reading Today 25, 3, 34.

Margolis, Rick. (2007) 'Stranger in a strange land’, School Library Journal 53, 9, 34. 
Pantaleo, Sylvia \& Sipe, Lawrence R. (2008) 'Introduction: postmodernism and picturebooks', in L. R. Sipe \& S. Pantaleo (eds.) Postmodern Picturebooks: Play, Parody, and Self-Referentiality. New York, Routledge, pp. 1-8.

Stephens, John. (2008) ““They are always surprised at what people throw away’: Glocal postmodernism in Australian picturebooks”', in L. R. Sipe \& S. Pantaleo (eds.) Postmodern Picturebooks: Play, Parody, and Self-Referentiality. New York, Routledge, pp. 89-102.

Tan, Shaun. (2001) 'Shaun Tan: out of context', Locus 47, 6, pp. 4-5, 74-75.

Tan, Shaun. (2006) The Arrival. New York, Arthur A. Levine.

Tan, Shaun. 'Comments on The Arrival.' Available from: http://www.shauntan.net/books/thearrival.html\#anchor [Accessed 30 March 2009].

Tan, Shaun. (2011) 'The accidental graphic novelist', Bookbird 49, 4, 1-9.

Yang, Gene Luen. (2007) 'Stranger in a strange land', New York Times Book Review, 11 Nov, 21.

\section{Biographical Note}

Dr. Ladislava Khailova is Associate Professor at Founders Memorial Library, Northern Illinois University, serving as a Humanities and Social Sciences Subject Specialist and Coordinator of Services for Students with Disabilities. Born in the Czech Republic, Khailova came to the United States as a Fulbright grantee to study 20th Century American literature with an emphasis on Southern literature, and, subsequently, information science. She earned a Ph.D. and an M.L.I.S. from the University of South Carolina and an M.A. in Russian and American Studies from Charles University in Prague. Her research interests gravitate towards the historical and cultural factors that shape constructions of the social other, be it in terms of disability, national origin, race, ethnicity, or gender. Khailova has published articles on American literature as well as on library science. She can be reached at khailova@niu.edu 